\title{
Studies of the Orientational Disorder at the Isotropic to Smectic-F Interface
}

\author{
S. Padmaja ${ }^{\mathrm{a}}$, M. Ramakrishna Nanchara Rao ${ }^{\mathrm{b}}$, P. V. Datta Prasad ${ }^{\mathrm{c}}$, and V. G. K. M. Pisipati ${ }^{\mathrm{a}}$ \\ a Centre for Liquid Crystal Research and Education, Acharya Nagarjuna University, \\ Nagarjunanagar 522 510, India \\ ${ }^{\mathrm{b}}$ Department of Physics, A.J. Kalasala, Machilipatnam, India \\ ${ }^{c}$ Department of Physics, Hindu College, Machilipatnam, India \\ Reprint requests to Prof. V.G.K.M.P.; E-mail: venkata_pisipati@ hotmail.com
}

Z. Naturforsch. 60a, 296 - 300 (2005); received December 20, 2004

Density studies on the isotropic to smectic-F transition in higher homologues of $N-(p-n$ alkoxybenzylidene)- $p$ - $n$-decylanilines ( $n \mathrm{O} .10)$ mesomorphic compounds with $n=13,14$ and 15 and corresponding studies on thermal expansion coefficient maxima confirm the first order nature of this transition. The density shows strong pretransitional fluctuations, which are estimated by $\alpha_{\text {eff }}$ in the vicinity of the mesomorphic fluctuation dominated non-linear region (FDNLR) of this phase transition. The growth of the density fluctuations across this transition is discussed in the light of data on the same transition in other compounds.

Key words: Orientational Order; Density; Smectic-F.

\section{Introduction}

The mesomorphic $N$-( $p$ - $n$-alkoxybenzylidene)- $p$ - $n$ alkylanilines $(n \mathrm{O} . m)$ compounds provide rich but subtle polymorphism [1]. Their higher homologues exhibit often a tilted smectic-F phase directly from the isotropic melt [2-6]. This phase with long range monoclinic tilt order and hexagonal molecular packing within the smectic layers (normal to the long axis of the molecules) has a quasi two-dimensional solid structure (i.e., poor correlation between layers). The smectic-F phase is a $2 \mathrm{D}$ system exhibiting long-range bond orientation with short-range positional order. The study of this phase transition and pretransitional effects reveal details of the molecular interactions. The reported density data across the isotropic smetic-F phase involves $10 \mathrm{O} .14$ [7], 12O.12, $12 \mathrm{O} .14$ and $12 \mathrm{O} .16$ [8] and $n \mathrm{O} .14$ [9] compounds in the $n$ O.m series. These compounds are divariant (FG) except 18O.14 (F) [1]. As part of the systematic studies on higher homologues of $n \mathrm{O} . m$ compounds, the present study involves density investigations in three $N$-( $p$ - $n$-alkoxybenzylidene)- $p$ - $n$ decylanilines $(n \mathrm{O} .10)$ mesomorphic compounds with $n=13,14$ and 15 , which are monovariant, exhibiting only the smectic-F liquid crystal phase between the isotropic and solid phases.

\section{Experimental}

The compounds $13 \mathrm{O} .10,14 \mathrm{O} .10$ and $15 \mathrm{O} .10$ were synthesized by the condensation reaction between the corresponding $p$ - $n$-alkoxybenzaldehyde $(0.01 \mathrm{~mole})$ and $p$ - $n$-decylaniline $(0.01$ mole) as described earlier $[6,10]$. The liquid crystalline phase identification and the transition temperatures were obtained by polarizing microscopy and differential scanning calorimetry. The density measurements were carried out [8] by an U-shaped bicapillay pyknometer. The absolute error in the density measurement was $10^{-4} \mathrm{mg} \cdot \mathrm{cm}^{-3}$. The cooling rate during the density measurement was $0.5{ }^{\circ} \mathrm{C} / \mathrm{h}$. The general molecular formula for $n \mathrm{O} .10$ compounds is

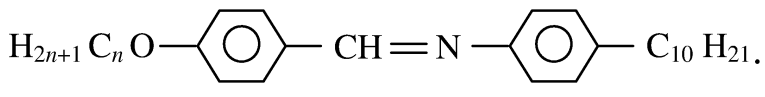

\section{Results and Discussion}

The transition temperatures $\left({ }^{\circ} \mathrm{C}\right)$ through thermal microscopy, differential scanning calorimetry and density methods, the density jumps $(\Delta \rho / \rho \cdot 100)$ and the thermal expansion coefficient maxima $(\alpha)$ at the transition, along with the data available for other $n \mathrm{O} . m$ 

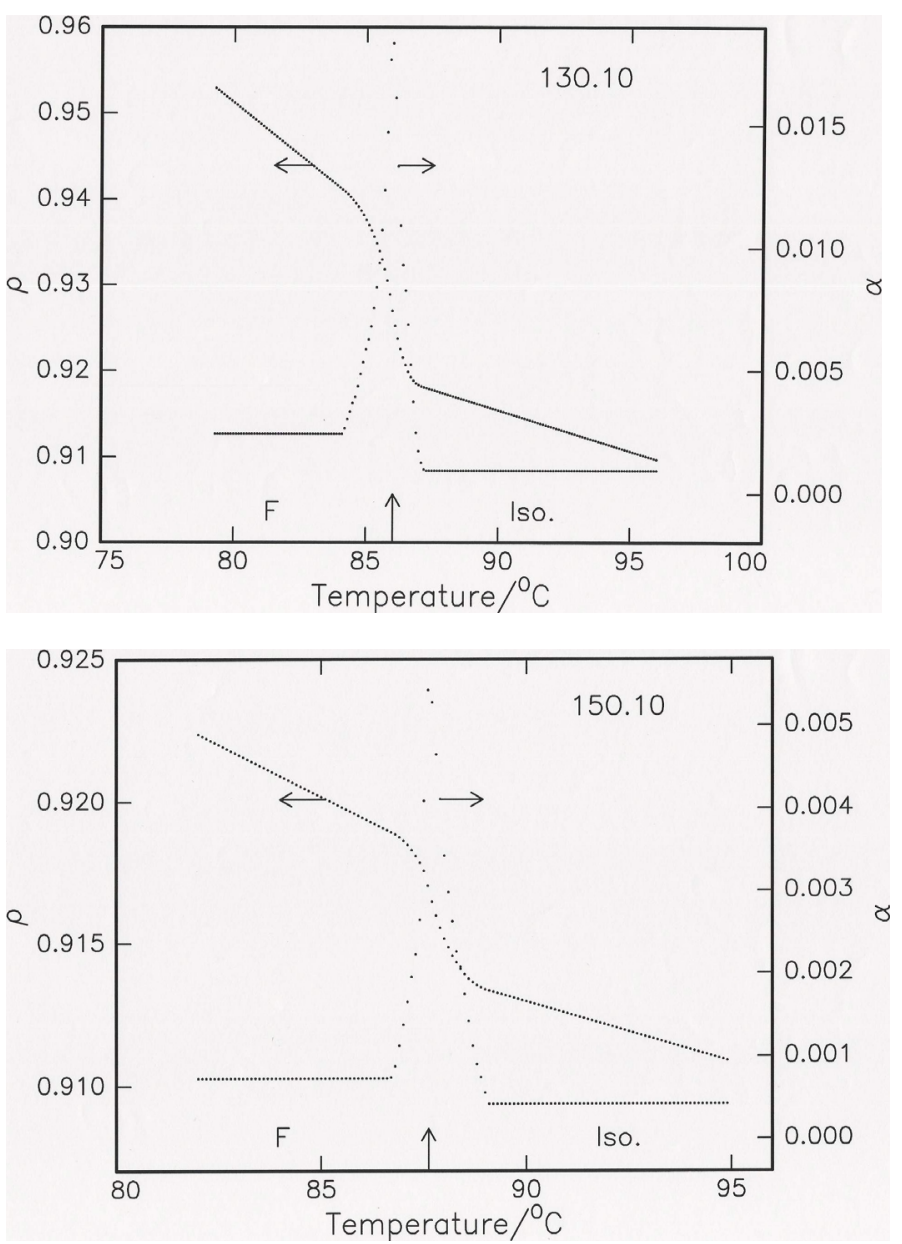

Fig. 1. Variation of the density $\left(\rho / \mathrm{mg} \cdot \mathrm{cm}^{-3}\right)$ and thermal expansion coefficient $(\alpha)$ with temperature for the compound $13 \mathrm{O} .10$.
Fig. 2. Variation of the density $\left(\rho / \mathrm{mg} \cdot \mathrm{cm}^{-3}\right)$ and thermal expansion coefficient $(\alpha)$ with temperature for the compound 140.10 .
Table 1. Transition temperatures (dilatometry), density jumps and thermal expansion coefficient maxima of compounds which exhibit iso-SmF transition in $n \mathrm{O} . m$ homologues.

\begin{tabular}{cccccc}
\hline Compound & $\begin{array}{c}\text { Phase } \\
\text { variant }\end{array}$ & $\begin{array}{c}\text { I-SmF trans- } \\
\text { ition temp. }\end{array}$ & $(\Delta \rho / \rho) \cdot 100$ & $\begin{array}{r}\alpha_{\max } / \\
10^{-4}{ }^{\circ} \mathrm{C}^{-1}\end{array}$ & Ref. \\
\hline $13 \mathrm{O} .10$ & $\mathrm{~F}$ & 86.0 & 2.47 & 183.3 & $\mathrm{PW}^{*}$ \\
140.10 & F & 91.4 & 1.01 & 78.5 & $\mathrm{PW}^{*}$ \\
150.10 & F & 87.6 & 0.57 & 54.3 & $\mathrm{PW}^{*}$ \\
$12 \mathrm{O} .12$ & FG & 88.0 & 0.94 & 116.1 & {$[3]$} \\
100.14 & FG & 83.4 & 2.14 & 295.0 & {$[7]$} \\
110.14 & FG & 88.5 & 0.33 & 54.0 & {$[9]$} \\
120.14 & FG & 87.4 & 0.81 & 136.3 & {$[3]$} \\
130.14 & FG & 87.8 & 0.50 & 125.0 & {$[9]$} \\
140.14 & FG & 88.4 & 0.17 & 110.0 & {$[9]$} \\
150.14 & FG & 88.5 & 1.20 & 132.0 & {$[9]$} \\
160.14 & FG & 87.8 & 0.11 & 95.0 & {$[9]$} \\
180.14 & F & 83.6 & 0.92 & 93.0 & {$[9]$} \\
120.16 & FG & 88.1 & 0.79 & 113.7 & {$[3]$} \\
\hline
\end{tabular}

* PW, present work. compounds which exhibit direct isotropic to smectic-F transitions are presented in Table 1 . The transition temperatures observed through different techniques show slight variations which may be due to the different rates of cooling. In 13O.m compounds 130.10 is the only compound which exhibits [6] a single phase variant, while in 140.m compounds four compounds with $m=8,9$ to 10 and 12 show [6] smectic-F single phase variants. The direct growth of smectic-F from the isotropic melt (with increase of a flexible end chain, alkoxy in the present case), along with the observations in the higher homologues with long end chains, agree with the mean field excluded volume theories [11] developed for micellar systems. It is observed in $n$ O. $m$ compounds that the ratio between terminal alkoxy and alkyl chains ( $n / m$ ratio) plays [12] a significant role in the origin and stabilization of the smectic-F phase. The values of the ratio in the case of 130.m 


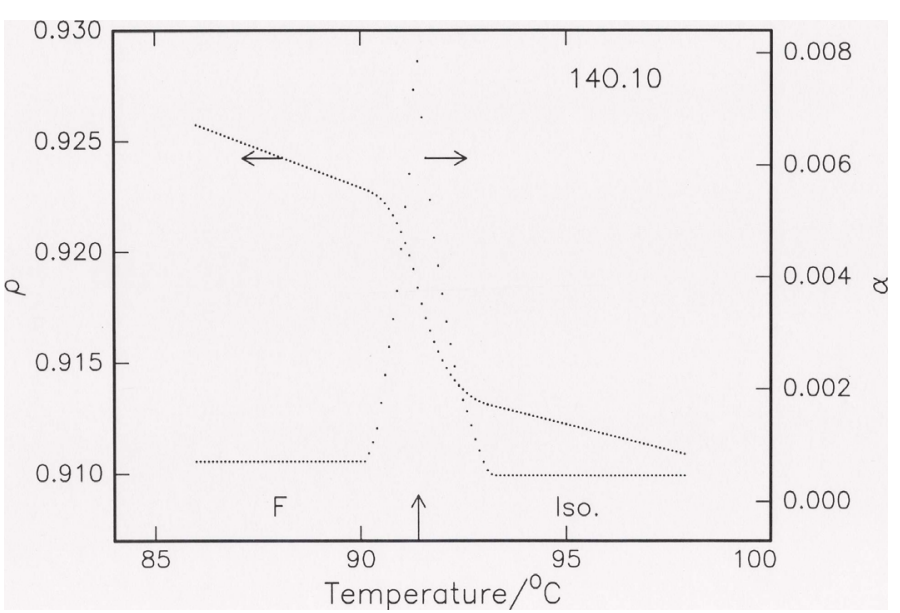

Fig. 3. Variation of the density $\left(\rho / \mathrm{mg} \cdot \mathrm{cm}^{-3}\right)$ and thermal expansion coefficient $(\alpha)$ with temperature for the compound 150.10 . and 140. $m$ compounds is $\geq 9$ and $\geq 8$, respectively, in agreement with predicted [12] values for these homologues.

The estimated molar volume in the isotropic phase per increment of the methylene group in these compounds at $\left(T_{\mathrm{IF}}+5{ }^{\circ} \mathrm{C}\right)$ is found to be in the range of 15.4 to $16.1 \cdot 10^{-6} \mathrm{~cm}^{3} \mathrm{~mol}^{-1}$, in agreement with the reported $[8,9,13]$ values for other $n$ O. $m$ compounds with $n=4$ to 12 and 15 . The rate of decrease of the density $(\mathrm{d} \rho / \mathrm{d} T)$ in isotropic phase is observed to be less in the case of 140.10 and 150.10 , while it is of the same order in the case of 130.10 reported for other liquid crystalline compounds. The temperature variation of density $\rho(T)$ and the thermal expansion coefficient $\alpha(T)$ for 13O.10, 140.10 and 15O.10 are shown in Figs. 1 to 3.

The isotropic to secrecy-F (IF) transition is indicated by a sudden jump in the density at $86.0{ }^{\circ} \mathrm{C}$ for $13 \mathrm{O} .10,91.4{ }^{\circ} \mathrm{C}$ for $14 \mathrm{O} .10$ and $87.6^{\circ} \mathrm{C}$ for $15 \mathrm{O} .10$. The density change $\Delta \rho / \rho$ at the IF transition is evaluated from the vertical distance between the extrapolated densities from the isotropic and smectic-F (I-SmF) regions. The sudden change of density at the transition and the thermal expansion coefficient maxima suggest that the transition is of first order. It is noticed that the density jumps in these compounds (Table 1) show decreasing with the increasing of alkoxy chain. The same trend (decrease of density jump with increase of alkyl chain) is observed [8] in the case of higher homologues of the 120.m series. A similar trend is reported [14] for the isotropic to smectic-C (I-SmC) transition in the TBnA series (14 to 16). However, in the case of the $n \mathrm{O} .14$ series, the density jump shows [9] an odd even effect with exception of 14O.14.

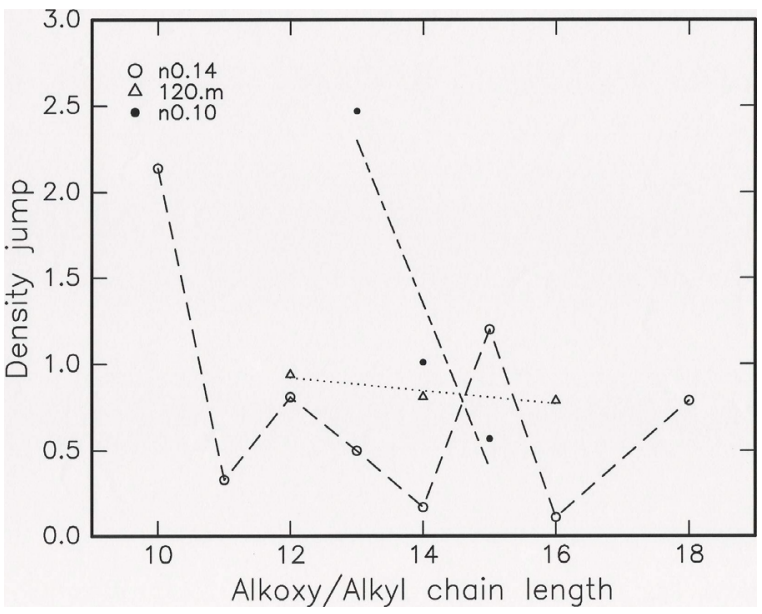

Fig. 4. Variation of the density jumps with the alkoxy/alkyl chain length in $n \mathrm{O} .14,12 \mathrm{O} . \mathrm{m}$ and $n \mathrm{O} .10$ compounds.

The density jump observed in the case of 13O.10 (2.57) is the maximum that is observed in the case of $n \mathrm{O} . \mathrm{m}$ compounds so far. The large density jump is due to the growth of the bond orientational order in smectic$F$ rather than the one dimensional orientational order in the case of the nematic phase. The reported variation in density jumps in $n$ O.m compounds (which exhibit isotropic-smectic-F transition) is shown in Fig. 4, which indicates that the effect of the alkoxy chain length plays a dominant role in effecting the jumps, i. e. decrease of the density jump with increase of the chain length. This is more prominent and pronounced with variation of the alkoxy chain $(n \mathrm{O} .10)$ rather than the alkyl chain length (12O.m). A different trend is observed in the case of the $n \mathrm{O} .14$ series, where an even odd effect is observed (with an exception in the case 


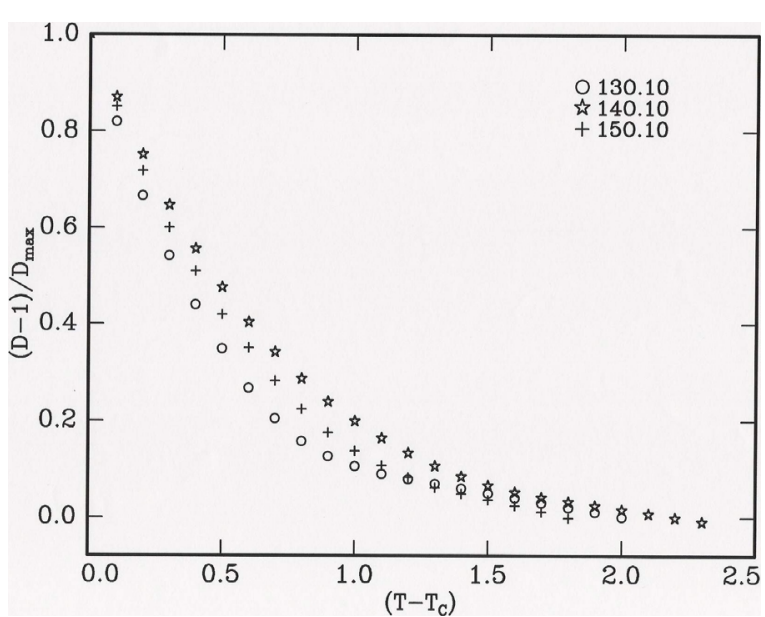

Fig. 5. Divergence of the density fluctuations $(D-1) / D_{\max }$ (where $D=\Delta \rho / \Delta \rho_{\max }$ ) near the transition point as a function of $\left(T-T_{\mathrm{C}}\right)$ for the three compounds.

of 140.14). However, the $n \mathrm{O} .14$ series of compounds exhibited maximal and minimal density jumps, 2.14 and 0.11 , respectively. Hence it may be argued that the alkoxy chain (rather than alkyl chain) plays a dominant role not only in the $n \mathrm{O} .10$ series but also in the $n \mathrm{O} .14$ series as it is manifested in a different way.

The trend of decreasing density jumps with increasing length of either of the two flexible end chains and the growth of tilted phases from the isotropic melt signifies a decreasing thermal potential barrier across the isotropic to the tilted mesomorphic interface. Increasing length of the flexible end chain possibly results in the favourable formation of a tilted smectic phase in higher compounds. These results agree with those of a 12O.m series [8] as well as with the isotropic to smectic-C transition in the TBnA series [14]. However, the interface of I-SmF in these compounds as well as in the 12O.m and $n \mathrm{O} .14$ series differs with the I$\mathrm{SmC}$ interface, as additional in-plane hexagonal positional correlations must be considered (in addition to the long-range tilt orientation in the I-SmC interface). Hence, as a result of higher symmetry breaking at the ISmF interface, the higher potential barrier is supposed to result in the higher density jump with increase of the flexible end chain. Even though the density jumps are relatively high compared to other interfaces, such as ISmA and I-SmC, the present compounds exhibited a similar decreasing trend with increase of the flexible end chain (alkoxy, $n \mathrm{O} .10$ series and alkyl, 12O.m series). In the wake of the studies across the I-SmC interface, the present systematic studies in the $n \mathrm{O} . m$ series

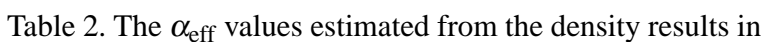
the FDNLR for first order I-SmF transitions.

\begin{tabular}{lccc}
\hline Compound & $\alpha_{\text {eff }} T>T_{\mathrm{C}}$ & $(\Delta T)_{\text {FDNLR }}$ range & Reference \\
\hline 130.10 & 0.48 & 2.0 & $\mathrm{PW}^{*}$ \\
$14 \mathrm{O} .10$ & 0.40 & 2.3 & $\mathrm{PW}^{*}$ \\
$15 \mathrm{O} .10$ & 0.36 & 1.8 & $\mathrm{PW}^{*}$ \\
$10 \mathrm{O} .14$ & 0.75 & 2.2 & {$[7]$} \\
$11 \mathrm{O} .14$ & 0.26 & 1.4 & {$[9]$} \\
$12 \mathrm{O} 12$ & 0.38 & 2.5 & {$[3]$} \\
$12 \mathrm{O} .14$ & 0.40 & 1.9 & {$[3]$} \\
$13 \mathrm{O} .14$ & 0.39 & 1.0 & {$[9]$} \\
$14 \mathrm{O} .14$ & 0.23 & 0.4 & {$[9]$} \\
$15 \mathrm{O} .14$ & 0.20 & 2.0 & {$[9]$} \\
$16 \mathrm{O} .14$ & 0.29 & 0.6 & {$[9]$} \\
18O.14 & 0.41 & 1.7 & {$[9]$} \\
12O.16 & 0.39 & 2.2 & {$[3]$} \\
\hline * PW, present work. & &
\end{tabular}

across the I-SmF interface demonstrate the dominant role of bond orientational order mediated tilt fluctuations for the formation of liquid crystal phase, which are obviously more prone to the temperature.

Although the density is found to increase linearly with decreasing temperature, its increment in density is found to be non-linear (the normalized density variation for $T>T_{\mathrm{IF}}$ is given in Fig. 5) in the vicinity of the isotropic to smectic-F phase transition. This type of non-linear variation of density on either sides of the transition temperature reflects the growth of the fluctuations which converge to a finite value at $T_{\mathrm{IF}}$. However, these fluctuations cease for $T<T_{\mathrm{IF}}$ before a thermally stabilized smectic-F phase is established with further decrease of the temperature. The strength and longevity of these pre-transitional fluctuations that grow at the I-SmF interface are estimated following the relation

$$
\left|\rho_{\mathrm{I}}-\rho_{\mathrm{c}}\right| \sim\left|T_{\mathrm{I}}-T_{\mathrm{c}}\right|\left(1-\alpha_{\mathrm{eff}}\right),
$$

where $\rho_{\mathrm{I}}$ is the observed density at the temperature of interest $T_{\mathrm{I}}$, and $\rho_{\mathrm{c}}$ the observed density at $T_{\mathrm{IF}}$. As $\Delta T=$ $\left|T_{\mathrm{I}}-T_{\mathrm{c}}\right|$, the fluctuation dominated non-linear region (FDNLR) reflects the persistence and longevity of the fluctuations at the growth. The exponent $\alpha_{\text {eff }}$ reflects the strength of the fluctuations.

The observed data of temperature variation and transition temperatures are fitted to the relation (1), and the resulting $\alpha_{\text {eff }}$ values along with the data of the thermal span of FDNLR are provided in Table 2. The goodness of the fit is demonstrated by the $p$-values $(>0.996)$ through the $\chi^{2}$-test in the present compounds. The trend of $\alpha_{\text {eff }}$ in the $n \mathrm{O} .14$ [9], 120.m [8] and $n \mathrm{O} .10$ series of compounds with increasing $n / m$ values is also 


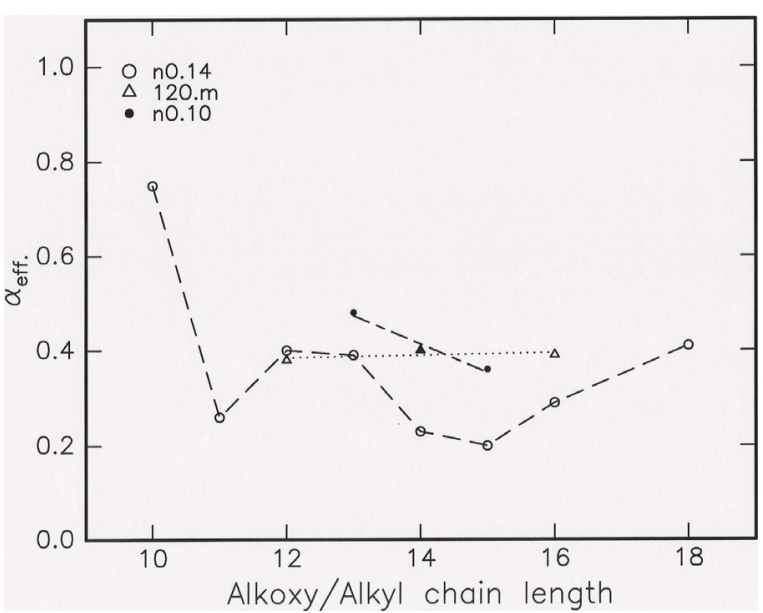

Fig. 6. The trend of $\alpha_{\text {eff }}$ in the $n$ O.14, 120.m and $n \mathrm{O} .10$ series of compounds with increasing alkoxy/alkyl chain lengths.

illustrated in Figure 6. It is observed that the trend of $\alpha_{\text {eff }}$ values (with increasing chain length) exhibited by the present compounds is much similar to the trend of density jumps presented in Figure 4. An over all trend of $\alpha_{\text {eff }}$ (or density jump) with increasing $n / m$ of these

[1] V. G. K. M. Pisipati, Z. Naturforsch. 58a, 661 (2003); C. Rama Chandra Prabhu, S. Lakshiminarayana, and V. G. K. M. Pisipati, Z. Naturforsch. 59a, 537 (2004).

[2] V. G. K. M. Pisipati, N. V.S. Rao, G. Padmaja Rani, and P. Bhaskara Rao, Mol. Cryst. Liq. Cryst. 210, 165 (1991).

[3] M. Srinivasulu, D. M. Potukuchi, and V. G. K. M. Pisipati, Z. Naturforsch. 52a, 713 (1997).

[4] M. Jitendra Nadh, C. G. Rama Rao, M. Srinivasulu, and V. G. K. M. Pisipati, Mol. Cryst. Liq. Cryst. 366, 47 (2001).

[5] V. G. K. M. Pisipati, A. K. George, Ch. Srinivasu, and P. N. Murty, Z. Naturforsch. 58a, 103 (2003).

[6] S. Padmaja, M. Srinivasulu, and V. G. K. M. Pisipati, Z. Naturforsch. 58a, 573 (2003).

[7] N. V. S. Rao, G. Padmaja Rani, D. M. Potukuchi, and V. G. K. M. Pisipati, Z. Naturforsch. 49a, 559 (1994). higher homologues in case of the $n \mathrm{O} .14$ [9], 12O.m [8] and $n \mathrm{O} .10$ series of compounds seems to decrease. It is also illustrating from Fig. 4, that the decreasing trend of $\alpha_{\text {eff }}$ values is rather steep and prominent in the case of the $n \mathrm{O} .14$ and $n \mathrm{O} .10$ series, when compared with the 12O.m series. This observed decreasing trend of $\alpha_{\text {eff }}$ is argued as due to the effective introduction of orientational disorder by the increase of the length of the flexible end chain. And hence, the orientational potential barrier experienced by a $n$ O. $m$ molecule during its condensation from the isotropic to the smectic$F$ matrix gets decreased, and this in turn decreases the $\alpha_{\text {eff }}$ (or $\Delta \rho$ ) values. However, this orientational disorder appears to be more effectively introduced by increasing the length of the end chain from the alkoxy side.

\section{Acknowledgements}

The authors thank Dr. D. M. Potukuchi, Assistant Professor, Department of Physics, JNTU, Kakinada, India. The financial support rendered by the Department of Science and Technology (Grant No. SP/S2/M34/ 2000), New Delhi, India is gratefully acknowledged.

[8] M. Srinivasulu, D. M. Potukuchi, and V. G. K. M. Pisipati, Z. Naturforsch. 52a, 713 (1997).

[9] M. Jitendra Nadh, C. G.Rama Rao, M. Srinivasulu, D. M. Potukuchi, and V. G. K. M. Pisipati, Mol. Cryst. Liq. Cryst. 366, 457 (2001).

[10] A. Wiegeleben, I. Richter, J. Deresch, and D. Demus, Mol. Cryst. Liq. Cryst. 59, 329 (1980).

[11] P. Van der School, J. Chem. Phys. 104, 1130 (1996).

[12] V. G. K. M. Pisipati, P. A. Kumar, and Ch. Srinivasu, Z. Naturforsch. 56a, 103 (2001).

[13] I. Haller, M. A. Huggins, H. R. Linnenthal, and T. R. Mc Guire, J. Chem. Phys. 77, 950 (1973).

[14] S. Lakshiminarayana, C. R. Prabhu, D. M. Potukuchi, N. V.S. Rao, and V. G. K. M. Pisipati, Liq, Cryst. 20, 177 (1996). 